\title{
Physiological Genetics of Aluminum Tolerance in the Wheat Cultivar Atlas 66
}

\author{
Y. Tang, D. F. Garvin,* L. V. Kochian, M. E. Sorrells, and B. F. Carver
}

\begin{abstract}
Aluminum toxicity limits wheat (Triticum aestivum L.) production on acidic soils. The wheat cultivar Atlas 66 reportedly may have both more than one Al tolerance gene and more than one Al tolerance mechanism. The purpose of this study was to identify the Al tolerance mechanisms conferred by the individual Atlas $66 \mathrm{Al}$ tolerance genes present in near-isogenic lines (NILs) of the cv. Century and Chisholm ('Century-T' and 'Chisholm-T'). Seedling hydroponic culture analysis revealed that the NILs were not as Al tolerant, nor were they able to exclude Al from root apices as effectively as Atlas 66. Al-inducible malate release from root apices was significantly higher in the NILs compared with the recurrent parents, but less than that observed in Atlas 66. In contrast, root phosphate release was significantly lower than previously reported in Atlas 66, with no major differences observed among lines. These results indicate that the Atlas $66 \mathrm{Al}$ tolerance gene present in each NIL acts by increasing Al-inducible malate release from root tips, but confers only a portion of the Al tolerance of Atlas 66 in both instances. Thus, differences in Al tolerance between the NILs and Atlas 66 can be attributed to malate release differences, and not differential phosphate release. Further, these results indicate that genetic variation at more than one locus underlies the malatemediated Al tolerance differences in Atlas 66, when compared with Century and Chisholm. The Atlas 66 alleles for these loci have not been introgressed into the NILs.
\end{abstract}

$\mathrm{A}^{\mathrm{t}}$ UMINUM TOXICITY is a limiting factor for crop production on acid soils, which comprise a significant fraction of the world's arable lands and include many areas of the tropics and subtropics (von Uexkull and Mutert, 1995). In acid soils, the predominant form of aluminum is $\mathrm{Al}^{3+}$, which stunts root system development and thus leads to chronic drought and nutrient deficiency stresses (Kochian, 1995). The development of Al-tolerant genotypes of many crop species has contributed greatly to increased crop productivity on acid soils, and future agricultural expansion onto acidic soils ensures that $\mathrm{Al}$ tolerance will remain an important crop improvement goal.

Potential mechanisms by which plants may tolerate Al have been postulated to exist (Taylor, 1991), but to date many of them are not firmly supported by experimental evidence. One exception is exclusion of $\mathrm{Al}$ from the root tip, achieved by Al-induced release of organic acids that chelate $\mathrm{Al}$ and thus prevent its entry into the root apex (Miyasaka et al., 1991; Delhaize et al., 1993b; Pellet et al., 1995; Ryan et al., 1995a, b). In wheat, malate

Y. Tang and L.V. Kochian, USDA-ARS, U.S. Plant, Soil and Nutrition Lab., Tower Road, Ithaca, NY 14853; B.F. Carver, Dep. of Crop and Soil Sciences, Oklahoma State Univ., Stillwater, OK 74078; M.E. Sorrells, Dep. of Plant Breeding, Cornell Univ., Ithaca, NY 14853; D.F. Garvin, USDA-ARS, Plant Science Research Unit, 411 Borlaug Hall, Univ. of Minnesota, 1991 Upper Buford Circle, St. Paul, MN 55108. Research supported by USDA-NRICGP award no. 97-351004501 to LVK, DFG, and MES. Received 2 Mar. 2001. *Corresponding author. (garvi007@umn.edu).

Published in Crop Sci. 42:1541-1546 (2002). is the predominant organic acid released in Al-tolerant but not Al-sensitive genotypes, and this response has been shown to cosegregate with $\mathrm{Al}$ tolerance (Delhaize et al., 1993b).

Another mechanism of $\mathrm{Al}$ tolerance in wheat has been proposed by Pellet et al. (1996), who reported that the highly Al-tolerant cultivar Atlas 66 exhibited not only Al-inducible malate release, but also constitutive release of phosphate, another Al-binding ligand, from root tips. As the latter was not observed in less Altolerant wheats studied, it was suggested that the tandem release of these two Al-binding ligands could explain the higher level of $\mathrm{Al}$ tolerance in Atlas 66. However, a test of the relative contribution of phosphate release to the $\mathrm{Al}$ tolerance of Atlas 66 is lacking.

The genetics of Al tolerance in wheat has been examined extensively. In many instances, Al tolerance variation between wheat varieties has been found to be under the control of a single gene difference (Kerridge and Kronstad, 1968; Camargo, 1984; Delhaize et al., 1993a; Somers and Gustafson, 1995; Riede and Anderson, 1996). However, there is also evidence to suggest that more than one $\mathrm{Al}$ tolerance gene may exist in certain wheat cultivars. Such reports have, interestingly, included Atlas 66 (Camargo, 1981; Berzonsky, 1992).

If multiple $\mathrm{Al}$ tolerance mechanisms exist in wheat, they would presumably be encoded by different genes. Evidence supporting the presence of both more than one gene and more than one mechanism of $\mathrm{Al}$ tolerance in Atlas 66 raises the possibility that different Atlas 66 $\mathrm{Al}$ tolerance genes may encode distinctly different $\mathrm{Al}$ tolerance mechanisms, specifically either Al-inducible malate or constitutive phosphate exudation from root tips. To examine this hypothesis, $\mathrm{Al}$ tolerance and physiological parameters associated with this trait, including malate and phosphate exudation, were measured in Atlas 66, the Al-sensitive cultivars Century and Chisholm, and Al-tolerant NILs of each of the latter cultivars that each contain an $\mathrm{Al}$ tolerance gene derived from Atlas 66 by backcross introgression (Carver et al., 1993; Johnson et al., 1997). By comparing and contrasting the experimental results between these genotypes, we sought to determine the mechanism of action of the Atlas 66 genes present in the NILs and to evaluate the contributions of malate and phosphate to the $\mathrm{Al}$ tolerance of Atlas 66, as a means of furthering our understanding of the physiological genetics of $\mathrm{Al}$ tolerance in Atlas 66 wheat.

\section{MATERIALS AND METHODS \\ Plant Material and Growth Conditions}

This study included the wheat cultivars Atlas 66, Century, and Chisholm, as well as Century-T and Chisholm-T, which

Abbreviations: ICP-ES, axial inductively coupled argon plasma atomic emission spectrometry; NIL, near-isogenic line; RRG, relative root growth. 
are Al-tolerant, $\mathrm{BC}_{3}$-derived NILs of Century and Chisholm. The source of $\mathrm{Al}$ tolerance present in the NILs was Atlas 66 (Carver et al., 1993). Each NIL has been shown to possess a single Atlas 66-derived Al tolerance gene, and there is evidence that supports the possibility that the individual Atlas $66 \mathrm{Al}$ tolerance gene present in each NIL is in fact the same locus (Johnson et al., 1997).

Seeds were surface sterilized with $0.5 \%(\mathrm{v} / \mathrm{v}) \mathrm{NaOCl}$ for 15 min, rinsed extensively with sterilized $\mathrm{H}_{2} \mathrm{O}$ for $15 \mathrm{~min}$, and placed on moist filter paper in petri dishes at $4^{\circ} \mathrm{C}$ for $5 \mathrm{~d}$ to synchronize germination across genotypes. The seeds were then moved to room temperature for $1 \mathrm{~d}$ to germinate, and transferred to a sterile hydroponic culture system consisting of 50-mL polypropylene Falcon centrifuge tubes (BD Biosciences, San Jose, CA) containing low-salt hydroponic medium $\left(200 \mu M \mathrm{CaCl}_{2}, \mathrm{pH}\right.$ 4.5). Three seedlings were placed together in plastic mesh-bottomed hollow polyethylene stoppers with the roots threaded through the mesh, and the stoppers were fitted into the tops of the Falcon tubes. The volume of the growth medium $(50 \mathrm{~mL})$ was sufficient to just contact the bottom of the mesh cup. Subsequently, the cups were filled with black polyethylene beads (DFDA-6080-black-4865, Union Carbide, Somerset, NJ) to maintain seedling placement. The tubes were arranged upright in racks, placed on a shaker platform, and rotated at 100 rotations per min at room temperature during experiments.

\section{Root Growth Evaluation of Al Tolerance}

After $48 \mathrm{~h}$ of growth, the longest root of each seedling was measured. The culture solution was then replaced with low salt media without $\mathrm{Al}$ (control) or with either 10,20 , or 30 $\mu M \mathrm{AlCl}_{3}$. After $24 \mathrm{~h}$ of additional growth, the longest root of each seedling was measured again. Al tolerance of the genotypes was expressed as relative root growth (RRG), calculated by dividing root growth in the presence of $\mathrm{Al}$ by root growth in control plants over the 24-h time period, and multiplying by 100 (Ryan et al., 1995b). The seedlings were saved for use in root tip Al quantification experiments, and the culture solution was frozen and saved until used for root exudation experiments. Each genotype-treatment combination was replicated five times.

\section{Hematoxylin Staining of Roots}

Plants were grown as described in the root growth Al tolerance evaluation experiment, rinsed extensively in distilled water for $1 \mathrm{~h}$, and submerged in a solution consisting of $0.2 \%$ (w/v) hematoxylin and $0.02 \%(w / v) \mathrm{KIO}_{3}$ for $30 \mathrm{~min}$. The roots were then washed with repeated changes of distilled water for $1 \mathrm{~h}$, and then evaluated for the degree of hematoxylin staining in root tips. Photographs of root tip staining patterns were taken with a dissection photomicroscope (Nikon Model 102, Nikon, Inc., Tokyo, Japan).

\section{Quantification of Al Accumulation in Root Tips}

Roots of seedlings from the root growth $\mathrm{Al}$ tolerance evaluation experiment were thoroughly rinsed in distilled water for $1 \mathrm{~h}$. The terminal $5 \mathrm{~mm}$ of each root was then excised from the seedlings, with the root tips from seedlings within a given tube bulked to form one sample. The root tips were dried overnight at $70^{\circ} \mathrm{C}$ in preweighed nickel boats, weighed, and transferred to quartz glass tubes and digested at $190^{\circ} \mathrm{C}$ for $2 \mathrm{~h}$ in $100 \mu \mathrm{L}$ of a $1: 1(\mathrm{v} / \mathrm{v})$ solution of concentrated, ultrapure $\mathrm{HNO}_{3}$ and $\mathrm{HClO}_{4}$. The resulting digestion product was dissolved in $2 \mathrm{~mL}$ of ultrapure $5 \%(\mathrm{v} / \mathrm{v}) \mathrm{HNO}_{3}$ and its $\mathrm{Al}$ content was determined via axial inductively coupled argon plasma atomic emission spectrometry (ICP-ES) (Sciex Model 5000, Perkin Elmer/Sciex, Concord, ON, Canada).

\section{Root Malate Exudation Analysis}

The solution from the root growth $\mathrm{Al}$ tolerance evaluation was centrifuged at $1600 \times g$ to remove debris, and concentrated to $5 \mathrm{~mL}$ by lyophilization. Malate was then quantified with a commercial kit (L-Malic Acid Enzymatic Analysis Kit, Roche Molecular Biochemicals, Mannheim, Germany). Briefly, $1 \mathrm{~mL}$ of glycylglycine buffer ( $0.6 M$ glycylglycine, $0.1 M$ L-glutamic acid, $\mathrm{pH} 10.0$ ) was mixed with $1 \mathrm{~mL}$ of concentrated root exudate solution, $0.2 \mathrm{~mL}$ of NAD ${ }^{+}$solution $(35 \mathrm{mg} / \mathrm{mL})$ and 40 enzymatic units of glutamate-oxaloacetate transaminase. The mix was incubated for approximately $5 \mathrm{~min}$ to stabilize chemical conditions in the reaction tube, and 60 units of malate dehydrogenase were then added to oxidize malate to oxaloacetate. This results in the production of $\mathrm{NADH}$ in direct proportion to the malate concentration in the sample. The NADH synthesized was measured spectrophotometrically at $340 \mathrm{~nm}$ (Beckman DU 640, Beckman Instruments, Fullerton, CA) and used to calculate malate concentrations. The assay was accurate across a range of malic acid concentrations, and $\mathrm{Al}$ did not interfere with measurements, as determined over a concentration range of 5 to $500 \mu M$ malate in the absence and presence of $1 \mathrm{mM} \mathrm{AlCl}$.

\section{Quantification of Root Phosphate Exudation}

Root phosphate exudation was quantified in samples of the same concentrated root exudate solution used for the malate quantitation, by the colorimetric malachite green method (Baykov et al., 1988). Ten milliliters of malachite green dye stock $\left[0.15 \%(\mathrm{w} / \mathrm{v})\right.$ in $\left.3 \mathrm{M} \mathrm{H}_{2} \mathrm{SO}_{4}\right]$ was mixed with $2.5 \mathrm{~mL}$ of $7.5 \%(\mathrm{w} / \mathrm{v})$ ammonium heptamolybdate and $0.2 \mathrm{~mL}$ of $11 \%$ (v/v) Tween. Subsequently, $0.15 \mathrm{~mL}$ of this freshly made dye mixture was mixed with $0.6 \mathrm{~mL}$ of the concentrated root exudate solution for $1 \mathrm{~h}$ at room temperature, and the absorbance at $630 \mathrm{~nm}$ was determined spectrophotometrically. The final phosphate concentration was determined via reference to a standard curve generated from measuring phosphate solutions ranging from 5 to $500 \mu M$.

\section{RESULTS}

\section{Aluminum Inhibition of Root Growth}

Differences in Al tolerance between Atlas 66, Century, Chisholm, and the Al-tolerant NILs Chisholm-T and Century-T were observed at all three solution $\mathrm{Al}$ concentrations evaluated (Fig. 1). Across all concentrations, Atlas 66 exhibited the greatest RRG values and was thus the most $\mathrm{Al}$ tolerant, while Chisholm exhibited the lowest RRG, followed by Century. In contrast, Century- $\mathrm{T}$ and Chisholm-T exhibited RRG values approximately the same as those observed for Atlas 66 at 10 $\mu M \mathrm{Al}$, but at higher $\mathrm{Al}$ levels the $\mathrm{RRG}$ for these lines decreased to values intermediate to those obtained for Atlas 66 vs. Century and Chisholm (Fig. 1). The relative Al tolerance ranking among the genotypes was Atlas66 $>$ Century-T $>$ Chisholm-T $>$ Century $>$ Chisholm.

\section{Hematoxylin Staining}

The degree of hematoxylin staining in root tips provides a semiquantitative measure of $\mathrm{Al}$ content in root 


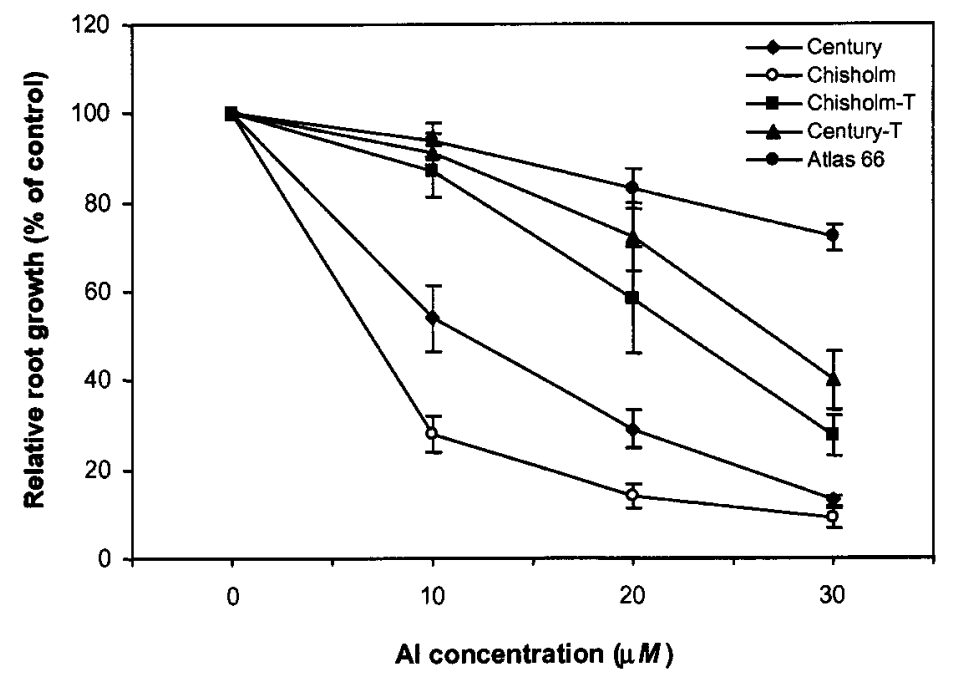

Fig. 1. Effect of increasing solution Al concentrations on the root elongation of seedlings of different wheat genotypes.

tips, and is inversely proportional to both the ability of a genotype to exclude Al from the root apex, and its Al tolerance (Polle et al., 1978). Staining was conducted on the wheat genotypes grown at each of the three solution $\mathrm{Al}$ concentrations. The terminal $5 \mathrm{~mm}$ of the root tips exhibited the greatest degree of staining, and the genotypes could be separated into three groups based on the root tip staining intensity. The best differentiation was observed at $20 \mu M \mathrm{Al}$, where root tips of Atlas 66 exhibited minimal staining, the root tips of Century-T and Chisholm-T were lightly stained, and the roots of Chisholm and Century were quite darkly stained (Fig. 2). The relative ranking of Al tolerance based on hematoxylin staining intensity was in agreement with the $\mathrm{Al}$ tolerance rankings based on RRG.

\section{Al Accumulation in Root Apices}

The terminal $5 \mathrm{~mm}$ of the roots from plants used for the root growth $\mathrm{Al}$ tolerance evaluation was analyzed by ICP-ES analysis to obtain root tip Al contents at all three $\mathrm{Al}$ concentrations (Fig. 3). In each genotype, root tip $\mathrm{Al}$ concentrations increased as $\mathrm{Al}$ concentrations increased. The five genotypes fell into three classes on the basis of the amount of $\mathrm{Al}$ accumulated in the root tip. At all solution $\mathrm{Al}$ concentrations, $\mathrm{Al}$ accumulation in Atlas 66 was dramatically lower than both of the Alsensitive varieties, while the Al-tolerant NILs accumulated intermediate levels of Al. These results are in concordance with the hematoxylin staining experiment. Thus, Al tolerance among genotypes as measured by Al-induced inhibition of root growth was positively correlated with the capacity of the genotypes to exclude $\mathrm{Al}$ from their root apices.

\section{Root Malate Exudation}

Aluminum-inducible exudation of malate from root tips of wheat is a well-known mechanism of excluding $\mathrm{Al}$ and thus obtaining Al tolerance (Delhaize et al., 1993b; Ryan et al., 1995a, b). Malate exudation was quantified in the wheat genotypes to determine if differences in exudation rates were present among the geno- types (Fig. 4). In the absence of $\mathrm{Al}$, the rate of root malate exudation was very low in all of the genotypes. However, when $\mathrm{Al}$ was present in the solution, the five genotypes could be separated into three groups on the basis of their Al-inducible malate exudation rates. $\mathrm{Al}$ exposure triggered significant malate release in Atlas 66 that increased with increasing $\mathrm{Al}$ concentrations, as previously observed (Pellet et al., 1996). In contrast, malate exudation increased minimally upon $\mathrm{Al}$ exposure in the Al-sensitive varieties. Rates of Al-induced malate exudation in Century- $\mathrm{T}$ and Chisholm- $\mathrm{T}$ were intermediate to those observed in Atlas 66 and the Alsensitive cultivars across $\mathrm{Al}$ concentrations.

\section{Root Phosphate Exudation}

A previous study suggested that constitutive phosphate exudation from the root apex in Atlas 66 could be a separate mechanism contributing to $\mathrm{Al}$ tolerance, in addition to $\mathrm{Al}$-inducible malate release that was present (Pellet et al., 1996). Root phosphate exudation was measured in all five genotypes (Fig. 5). While in general Atlas 66 appeared to exhibit higher levels of root phos-

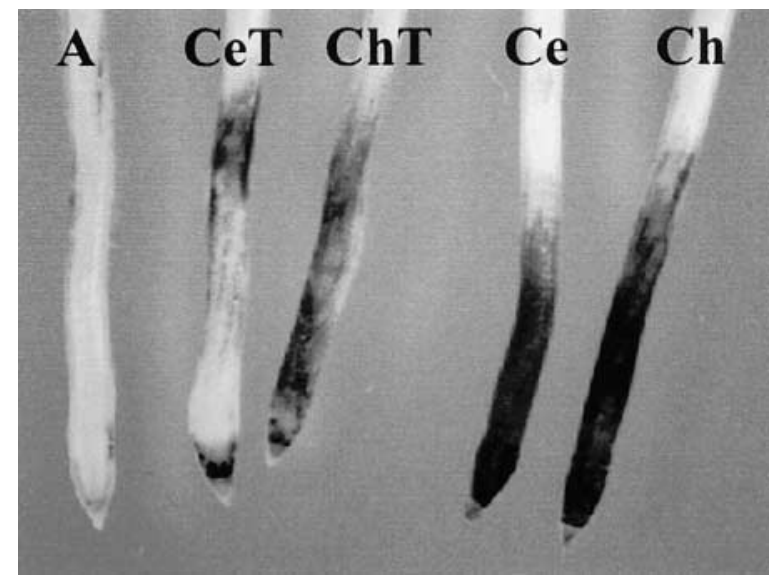

Fig. 2. Hematoxylin staining of root apices of wheat genotypes grown in $200 \mu M \mathrm{CaCl}_{2}$ solution, $\mathrm{pH}$ 4.5, containing $20 \mu M \mathrm{AlCl}_{3}$. Roots were stained after $24 \mathrm{~h}$ of exposure to Al. A, Atlas 66; Ce, Century; Ch, Chisholm; CeT, Century-T; ChT, Chisholm-T. 


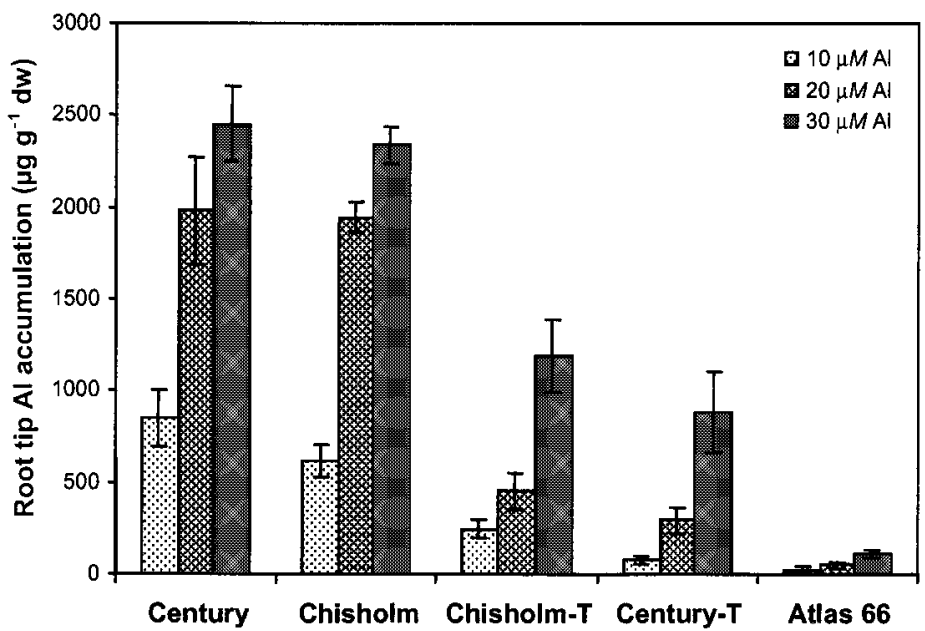

Fig. 3. Al accumulation in root apices of different wheat genotypes grown hydroponically across a range of Al concentrations.

phate release than did the other wheat genotypes at some of the solution $\mathrm{Al}$ concentrations, the differences were at best minor, particularly when considered within the context of a potential contribution to $\mathrm{Al}$ exclusion. Indeed, in Atlas 66 the rate of phosphate efflux was 15 to 80 times smaller than $\mathrm{Al}$-induced rates of malate release. Further, the rates of root phosphate release in Atlas 66 were significantly $(4.5-23 \times)$ lower than those presented previously by Pellet et al. (1996). In the previous study, phosphate release was only measured over a 7-h period, compared with $24 \mathrm{~h}$ in this study. It is therefore possible that the enhanced root apical phosphate release previously reported in Atlas 66 was only transient.

\section{DISCUSSION}

Despite a significant cumulative amount of research on the topic, we still do not have a comprehensive understanding of the number of genes and mechanisms for $\mathrm{Al}$ tolerance that exist in wheat. Some inheritance studies have suggested that Atlas 66 wheat harbors two $\mathrm{Al}$ tolerance genes (Camargo, 1981; Berzonsky, 1992). It was therefore intriguing that Atlas 66 was also reported to possess two distinct mechanisms of $\mathrm{Al}$ tolerance, in the form of constitutive phosphate release and Al-inducible malate release from the root apices (Pellet et al., 1996). While there is firm genetic evidence supporting the malate-based mechanism of $\mathrm{Al}$ tolerance (Delhaize et al., 1993b), such evidence does not yet exist for the proposed phosphate mechanism. We hypothesized that the two Al tolerance genes reported to exist in Atlas 66 could separately encode one of these two mechanisms, and our study sought to test this hypothesis by comparative analysis of Al tolerance and related physiological parameters in Atlas 66 and the Al-tolerant NILs of Century and Chisholm.

The results of our solution culture analysis of $\mathrm{Al}$ tolerance demonstrate that neither Century-T nor Chisholm- $\mathrm{T}$, which each contain an $\mathrm{Al}$ tolerance gene from Atlas 66, possesses the same level of $\mathrm{Al}$ tolerance as Atlas 66, as suggested previously (Johnson et al., 1997). This result provided the incentive to analyze physiological parameters associated with $\mathrm{Al}$ tolerance in Atlas 66 and the NILs, to determine which mechanisms associated with $\mathrm{Al}$ tolerance in Atlas 66 were either present or absent in the NILs. Our analysis of root tip Al accumulation in the different genotypes clearly indicates that the Atlas 66-derived Al tolerance genes in both

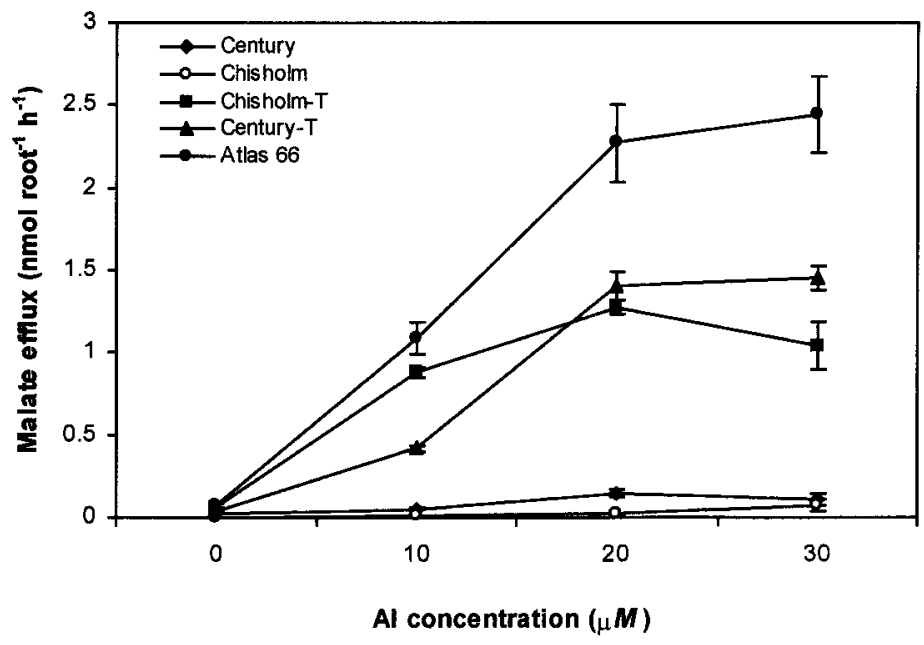

Fig. 4. Influence of different solution Al concentrations on rates of root tip malate efflux by different wheat genotypes. 


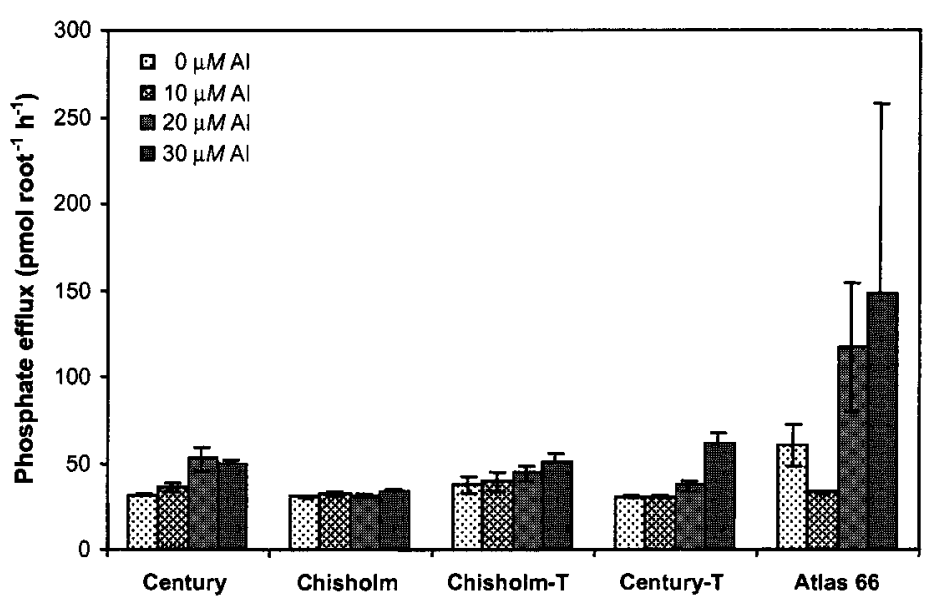

Fig. 5. Influence of solution Al concentration on rates of root phosphate efflux by different wheat genotypes.

Century- $\mathrm{T}$ and Chisholm- $\mathrm{T}$ enhance $\mathrm{Al}$ tolerance by an $\mathrm{Al}$ exclusion mechanism. However, it is equally evident that when present in Century and Chisholm, the individual genes do not by themselves confer the same $\mathrm{Al}$ exclusion capacity observed in Atlas 66. The root apex is the site of Al toxicity (Ryan et al., 1993), and thus the reduced ability of the NILs to exclude $\mathrm{Al}$ from this region compared with Atlas 66 is presumed to be the biological basis for the lower level of $\mathrm{Al}$ tolerance in the NILs.

We hypothesized that the reduced $\mathrm{Al}$ exclusion capacity of the NILs relative to Atlas 66 could reflect the fact that the individual $\mathrm{Al}$ tolerance genes introgressed into each NIL could encode either constitutive root tip phosphate release or Al-inducible malate release, and that a gene(s) encoding the other mechanism was not transferred. Results of phosphate and malate quantitation did not support this hypothesis. We used an improved method both for gathering and quantifying phosphate exuded by roots, and we were unable to confirm that constitutive phosphate efflux is large enough to be of significance to the $\mathrm{Al}$ tolerance in Atlas 66. Given this result, the difference in both $\mathrm{Al}$ exclusion and $\mathrm{Al}$ tolerance between the NILs and Atlas 66 cannot be attributed to the presence of a gene encoding constitutive phosphate release in Atlas 66 that was not transferred to the NILs, as we had originally hypothesized.

The physiological basis for the differences in Al tolerance between Atlas 66 and the NILs was instead revealed by the results of the malate exudation analysis. Both Chisholm and Century exhibited minimal malate release, but their respective NILs exhibited significant Al-inducible malate release. This demonstrated that the individual Atlas $66 \mathrm{Al}$ tolerance genes in each NIL act by increasing $\mathrm{Al}$-inducible malate release. This is the same mechanism shown to be conferred by the Alt1 gene derived from cv. Carazinho (Delhaize et al., 1993b). Nonetheless, the amount of malate released by the NILs was not as great as observed in Atlas 66. These results indicate that both the reduced $\mathrm{Al}$ exclusion capacity and reduced $\mathrm{Al}$ tolerance of the NILs compared with Atlas 66 can be ascribed to less malate efflux from the root tips of the NILs after Al exposure.

From our comparative analysis of Atlas 66 and the
NILs, it is evident that to reconstitute Atlas $66 \mathrm{Al}$ tolerance levels fully in Century and Chisholm, the introgression of more than one gene from Atlas 66 is required. Alternative scenarios regarding the number of such genes as well as gene action is worthy of speculation, because of its relevance to choosing the best selection method for the Al tolerance trait. A previous study (Johnson et al., 1997) provided evidence that the Atlas 66 gene in each NIL may be the same locus. If so, then the $\mathrm{Al}$ tolerance difference between Atlas 66 and the NILs may involve allelic differences at "modifier loci." For instance, Atlas 66 may harbor alleles at loci that enhance malate exudation in the presence of bona fide $\mathrm{Al}$ tolerance genes such as those in the NILs. Alternatively, Atlas 66 could hypothetically possess nonfunctional alleles of malate exudation suppressor loci, whereas Century and Chisholm may have functional alleles at these same loci that suppress the activity of the introgressed Atlas $66 \mathrm{Al}$ tolerance gene. The summed effect of such modifier loci could produce a "background effect" manifested as incomplete expression of the $\mathrm{Al}$ tolerance gene. In contrast, if new evidence emerges demonstrating that the genes in the NILs are different, in contrast to the conclusions of Johnson et al. (1997), then this would indicate that Atlas 66 harbors two distinct loci encoding the same mechanism of $\mathrm{Al}$ tolerance. If so, Atlas 66 is likely to be more $\mathrm{Al}$ tolerant than the NILs because it harbors both of the genes. In either instance, our results demonstrate both that more than one gene difference contributes to the malate-based $\mathrm{Al}$ tolerance of Atlas 66 relative to Century and Chisholm, and that the Atlas 66 alleles of these genes have been excluded from the NILs.

For an $\mathrm{Al}$ tolerance mechanism such as $\mathrm{Al}$-induced malate release, a number of cellular processes associated with organic acid synthesis and metabolism, compartmentation and transport are likely to be involved. Thus, allelic variation at a number of different loci could hypothetically influence the efficacy of this Al tolerance mechanism. Aniol and Gustafson (1984) reported that the loss of a number of different chromosome arms of wheat reduced $\mathrm{Al}$ tolerance. Among these lines, the loss of the short arm of chromosome $5 \mathrm{~A}$ or $7 \mathrm{~A}$, or the long arm of chromosome $4 \mathrm{D}$, results in a much lower rate 
of Al-induced malate release from the root apex (Papernik et al., 2001). Thus, these chromosome arms contain genes at which natural variation could modify $\mathrm{Al}$ tolerance because of changes in malate release. Molecular genetic studies should provide additional information on the genome locations of additional Atlas 66 genes that influence $\mathrm{Al}$ tolerance by modulating malate exudation.

\section{ACKNOWLEDGMENTS}

The authors thank Jon Shaff for his technical expertise and assistance with root exudate measurements.

\section{REFERENCES}

Aniol, A., and J.P. Gustafson. 1984. Chromosome location of genes controlling aluminum tolerance in wheat, rye, and triticale. Can. J. Genet. Cytol. 26:701-705.

Baykov, A.A., O.A. Evtushenko, and S.M. Avaeva. 1988. A malachite green procedure for orthophosphate determination and its use in alkaine phostphatase-based enzyme immunoassay. Anal. Biochem. 171:266-270.

Berzonsky, W.A. 1992. The genomic inheritance of aluminum tolerance in 'Atlas 66' wheat. Genome 35:689-693.

Camargo, C.E.O. 1981. Melhoramento do trigo. I. Hereditariedade da tolerancia a toxicidade do aluminio. Bragantia 40:33-45.

Camargo, C.E.O. 1984. Melhoramento do trigo. VI. Hereditariedade da tolerancia a tres concentracoes de aluminio em solucao nutritiva. Bragantia 43:279-291.

Carver, B.F., W.E. Whitmore, E.L. Smith, and L. Bona. 1993. Registration of four aluminum-tolerant winter wheat germplasms and two susceptible near-isolines. Crop Sci. 33:1113-1114.

Delhaize, E., S. Craig, C.D. Beaton, R.J. Bennet, V.C. Jagadish, and P.J. Randall. 1993a. Aluminum tolerance in wheat (Triticum aestivum L.). I. Uptake and distribution of aluminum in root apices. Plant Physiol. 103:685-693.

Delhaize, E., P.R. Ryan, and P.J. Randall. 1993b. Aluminum tolerance in wheat (Triticum aestivum L.). II. Aluminum-stimulated excretion of malic acid from root apices. Plant Physiol. 103:695-702.

Johnson, J.P. Jr., B.F. Carver, and V.C. Baligar. 1997. Expression of aluminum tolerance transferred from Atlas 66 to hard winter wheat. Crop Sci. 37:103-108.

Kerridge, P.C., and W.E. Kronstad. 1968. Evidence of genetic resistance to aluminum toxicity in wheat (Triticum aestivum Vill., Host). Agron. J. 60:710-711.

Kochian, L.V. 1995. Cellular mechanisms of aluminum toxicity and resistance in plants. Annu. Rev. Plant Physiol. Plant Mol. Biol. 46: 237-260.

Miyasaka, S.C., J.G. Buta, R.K. Howell, and C.D. Foy. 1991. Mechanism of aluminum tolerance in snapbeans: Root exudation of citric acid. Plant Physiol. 96:737-743.

Papernik, L.A., A.S. Bethea, T.E. Singleton, J.V. Magalhaes, D.F. Garvin, and L.V. Kochian. 2001. Mechanistic basis of Al sensitivity in the ditelosomic lines of Chinese Spring wheat. Planta 212:829834.

Pellet, D.M., D.L. Grunes, and L.V. Kochian. 1995. Organic acid exudation as an aluminum tolerance mechanism in maize. Planta 196 788-795.

Pellet, D.M., L.A. Papernik, and L.V. Kochian. 1996. Multiple aluminum-resistance mechanisms in wheat. Roles of root apical phosphate and malate exudation. Plant Physiol. 112:591-597.

Polle, E., C.F. Konzak, and J.A. Kittrick. 1978. Visual detection of aluminum tolerance levels in wheat by hematoxylin staining of seedling roots. Crop Sci. 18:823-827.

Riede, C.R., and J.A. Anderson. 1996. Linkage of RFLP markers to an aluminum tolerance gene in wheat. Crop Sci. 36:905-909.

Ryan, P.R., J.M. DiTomaso, and L.V. Kochian. 1993. Aluminun toxicity in roots: An investigation of spatial sensitivity and the role of the root cap. J. Exp. Bot. 44:437-446.

Ryan, P.R., E. Delhaize, and P.J. Randall. 1995a. Characterisation of Al-stimulated efflux of malate from the apices of Al-tolerant wheat roots. Planta 196:103-110

Ryan, P.R., E. Delhaize, and P.J. Randall. 1995b. Malate efflux from root apices and tolerance to aluminium are highly correlated in wheat. Aust. J. Plant Physiol. 22:531-536.

Somers, D.J., and J.P. Gustafson. 1995. The expression of aluminum stress induced polypeptides in a population segregating for aluminum tolerance in wheat (Triticum aestivum L.). Genome 38:12131220.

Taylor, G.J. 1991. Current views of the aluminum stress response The physiological basis of tolerance. Curr. Topics Plant Biochem. Physiol. 10:57-93.

von Uexkull, H.R., and E. Mutert. 1995. Global extent, development and economic impact of acid soils. p. 5-19. In R.A. Date et al. (ed.) Plant-Soil interactions at low $\mathrm{pH}$ : Principles and management. Kluwer Academic Publishers, Dordrecht, the Netherlands. 